\title{
Motivators of Job Satisfaction Among Financial Managers and The Role of Gender
}

By

Mark Mattia, University of South Florida

$\mathrm{D}$ espite extensive efforts to recruit females to the financial management sector, women in the industry remain a distinct minority. For instance, only $23 \%$ of Certified Financial Planners (CFP's) are women (CFP Board, 2019). Additionally, more executive females and senior managers $(23 \%)$ exit the financial services labor market compared to males at the same levels (17\%) (Mercer Study, 2016). This paper utilizes the 2017 National Survey of College Graduates to examine the motivational factors related to job satisfaction among males and females in the financial management field. Research findings reveal that highly intrinsic job satisfaction factors that can be considered more intrinsic are more highly correlated with overall job satisfaction for females. Correlations of the factors with job satisfaction tend to be higher for females compared to their male peers. The female model of job satisfaction produced odds ratios that were the highest for two intrinsic type motivator variables (intellectual challenge and degree of independence). Among male financial managers, the odds ratios were the highest for two extrinsic motivators (salary and job security). These findings are promising in terms of relating Self-Determination Theory (STD) and motivation among financial managers. Such findings provide the impetus for original survey research incorporating the Motivation at Work Scale to explore more deeply the connection of STD and work motivation in the financial services areas.

Keywords: Financial management, gender, financial services, financial planning, job satisfaction, work motivation, Self-Determination Theory

Copyright ( 2020 , Mark Mattia. This article is published under a Creative Commons BY-NC license. Permission is granted to copy and distribute this article for non-commercial purposes, in both printed and electronic formats 


\section{Introduction}

Financial services sectors actively recruit female college graduates with finance degrees and those with financial services certifications. The pipeline of female recruits into the financial services segment is augmented by the rapid growth of financial planning departments at major colleges around the country (Chandler, 2016). However, the retention of females in the financial management field (particularly in the financial planning field) has proven elusive. Moreover, the representation of women in top financial positions of financial services companies pales in comparison to their male counterparts (Mercer Study, 2016). Part of understanding retention in the field is to understand the motivators for job satisfaction, affective commitment, and turnover intention. In this study, I investigate the first of these three possible outcome variables with respect to possible motivators overall and by gender.

The purpose of this study is twofold. The first is to understand the drivers for job satisfaction among males and females in the financial management (or closely related) field. The study participants have at least undergraduate degrees in finance. This inclusion is significant to business practices since positive job satisfaction is strongly linked to affective work commitment, which is strongly and inversely linked with intention to leave the position (See for instance, Williams \& Haz-

er, 1986; Meyer et al., 1993; Lambert \& Hogan, 2009; Pepe, 2010). Secondly, I examine the relationship between job satisfaction and the satisfaction drivers with consideration of gender as a possible determinant.

Ultimately, Self-Determination Theory (SDT) may help explain the lack of retention of women in the financial management field. This theory holds that people can be motivated by intrinsic or autonomous motivation factors (work is done for the benefit of doing it) and extrinsic motivation factors (work is done for some separable outcome, such as tangible rewards). In SDT, the intrinsic factors are segmented into three primary areas: autonomy, relatedness, and competence. Work motivation studies that have incorporated aspects of SDT to model work satisfaction and job retention have been positive. This analysis is a first step toward understanding the role that parts of the theory may play in understanding the motivational factors contributing to job satisfaction within the financial management sector. In this study, high levels of correlation and significant regression coefficients are shown to exist for several variables (intrinsic and extrinsically oriented) with respect to overall job satisfaction.

\section{Research Questions}

I consider two major research questions in this study. They are:

RQ1: What determinants are associated with financial management degreed participants being satisfied with their current positions in financial management?

RQ2: To what degree does gender play a role in determining job satisfaction among financial managers?

\section{Review of Research}

\section{Job Satisfaction and Self-Determination Theory}

The predominant literature that addresses the first research problem is dedicated to studying work motivation and job satisfaction. Theories that have been developed to address the linkage between motivation and job satisfaction. include: Dispositional Theory, Hierarchy of Needs Theory, Expectancy Theory, Job Characteristics Theory, and Self-Determination Theory. As an example, Herzberg et al. (1959) linked satisfaction with motivation and created a two-factor model (Mattia, 2020). Self-Determination Theory has been in literature for more than four decades. Such literature details the concepts of autonomy, competence, and relatedness as fundamental to a person's well-being. Specifically, need satisfaction areas should be nurtured and addressed in life and at work. The primary differentiator for the theory is "the relative strength of autonomous motivation versus controlled motivation" (Gagné \& Deci, 2005). Autonomous motivation is typically a derived aggregate of intrinsic motivation elements. For this study, we consider and test several intrinsic type motivators. These include: "Job is an intellectual challenge," "degree of independence," and "societal contributions of the job." The idea that intellectual challenge may be considered intrinsic originates with Gagné and Deci (2005), who view the challenge of the job as an environmental aspect that acts as an antecedent of autonomous motivation.

The relationship of SDT with overall well-being is explained in the seminal work of Ryan and Deci (2000). Deci et al. (2001) found positive relations in two countries between levels of intrinsic motivation and work engagement and job well-being. Baard et al. (2004) found Self-Determination Theory related to motivation in the workplace. Since about 2005, aspects of positive psychology, particularly SDT, have been utilized to address employee needs and states 


\section{Methodology}

The data for the study was taken from the National Survey of College Graduates (NSCG), which is conducted in wave fashion; the particular wave used for this study was completed in early 2017. The U.S. Census Bureau is responsible for the NSCG data collection. The NSCG "uses a trimodal data collection approach: online survey, mail questionnaire, and telephone interview." (https://census.gov/programs-surveys/nscg/about.html). Respondents were drawn from the American Community Survey. The respondents have at least a bachelor's degree earned prior to 2016, are under the age of 76, and live in the United States. The 2017 NSCG includes 124,000 sample cases with the response unit being those who have attained at least a bachelor's degree.

The data was collected under the direction of the National Science Foundation. According to the National Science Foundation, the NSGC items were pretested in focus groups and cognitive interviews to reduce measurement errors. Sampling error estimates associated with this survey were calculated using replicate weights, and the weighted response rate was $71 \%$ (with adjustments made to reduce non-response bias; https://www.nsf.gov/statistics/srvygrads/\#sd.) The variables and scales in the study have been utilized for numerous years and in many other research documents.

The survey allows for the studying of relationships between respondents' degree field and their current field of work. Key for the present analysis, the data base also includes factors that can be analyzed as possible determinants for respondent job satisfaction and other factors that can be viewed as reasons for not working in the field of study. The survey is dedicated primarily to those in the engineering and science fields; however, many other segments of the work force (including business and the financial management sub segment of business) are included. Following Hunt (2016), we only consider respondents under 66 years old. Several types of analyses have been conducted, including descriptive analysis, hypothesis testing, correlation analysis, and logistic regression modelling. We also include the intrinsic and extrinsic type motivators among the possible factors driving job satisfaction and other possible factors for those respondents employed in the financial management or closely related field. We analyze whether gender plays a role in job satisfaction among the respondents via correlational and logistical regression analyses. All of the regression analysis was conducted using Statistical Analysis Software (SAS), version SAS 9.4 TS1M3..The T-test procedure for comparison of job satisfaction by gender was conducted in Jeffreys's Amazing Statistics Program. (JASP), version 0.14.

The survey instrument is limited with respect to the number of intrinsic and extrinsic motivators it contains. Competency is a major element of Self-Determination Theory, and we are able to examine perceptions of competency through the attribute, job is an intellectual challenge. We are greatly limited in terms of inclusion of the STD element, autonomy. For this study, we can utilize the job's degree of independence as a possible intrinsic factor. However, I acknowledge autonomy and independence are not the same. Independence can imply a rejection of dependence, which acts contrarily with another important STD need, relatedness. However, independence is the closest attribute we had available presently, and I can consider it an intrinsic attribute, if not an SDT element. The data set affords a fair number of extrinsic motivators to be examined, including satisfaction with salary, benefits, job security, and opportunities for advancement. The primary analyses for all the considerations in the study are inferential statistic through the use of Ordinal Logistic Regression.

Variables such as job location and level of responsibility are considered "other" variables as are other respondent characteristics, such as having an MBA or certifications, such as the Certified Financial Planner (CFP) or Chartered Financial Analyst (CFA). The variables are defined in Table 1.

The primary outcome measures are the significance levels of the factors (Chi Square values), the odds ratios and their corresponding confidence intervals, the model concordance percentages, and the comparison of the female and male models.

of satisfaction (Gagne \& Koestner, 2002; Meyer \& Gagne, 2008). Intrinsic motivation has been found to be positively related to job satisfaction (Gillet et al., 2013, Guntert, 2015). In a meta-analytic study, Van den Broeck et al. (2016) found that the satisfaction of the basic needs of autonomy, competence, and relatedness are related to higher job satisfaction. Research and confirmations of the theory in practice are mainly in the areas of education, sports, health care, and more general work areas, such as the factory worker labor force. To my knowledge, applications of SDT or SDT type motivators to the world of financial management or financial services management have not been published. Since the retention of females in the business sector remains problematic, we expect SDT to eventually provide insights into this dilemma. For this study, we examine and test the following three hypotheses: 


\section{Research Hypotheses}

H1) The intrinsic motivation factor "job is an intellectual challenge" will be associated positively with overall job satisfaction among male and female financial managers employed in financial management.

H2) The intrinsic motivation factor "degree of independence" will be associated positively with overall job satisfaction among male and female financial managers employed in financial management.

H3) Motivation factors driving job satisfaction among financial managers fully employed in financial management will be the same for males and females.

Gender, Job Satisfaction, and The Financial Management Profession

Conclusions from studies involving the role of gender on work satisfaction have pointed toward women having higher levels. Studies by Sousa-Poza and Sousa-Poza (2000) and Sloane and Williams (2000) have found that women tend to have higher levels of job satisfaction. Bender et al. (2005) also report that women have higher job satisfaction than men. Sousa-Poza and Sousa-Poza (2000) also found that the determinants of job satisfaction (from a workrole input perspective) did not differ when comparing males and females. One exception being that females appear to value relationships with management more while males value compensation more.

Thompson and Prottas (2006) find that gender correlated with stress and job satisfaction, with women reporting higher levels of both. In a more recent study, Stefko et al. (2017) claim that women and men differ in terms of the need to have supervisor recognition, (a form of extrinsic motivation). In the same study, it was found that gender differences occurred for demotivating job aspects in only two of twenty variables considered. These include having unjust conduct from a superior and having an unstable job; in both contexts, women were more demotivated (Stefko et al., 2017). Among other variables that could be considered extrinsic, no gender differences were discovered when considering determinants of job satisfaction in the workplace. Also, Vansteenkiste et al. (2007) found no differences in job satisfaction due to gender in a two sample differences test.

A review of the literature reveals little direct work concerning the combination of women, job satisfaction, retention rates in financial management, and reasons for well-being on the job. In a mixed methods approach, Neck (2015) suggests that women leave their financial positions "due to a combination of frustration, change and choice (pp. 533)." While her conclusions are based on analyses from her open-ended questions and quantitative survey, she does not attempt to explain the results fully within any theoretical framework. Hunt's (2016) study

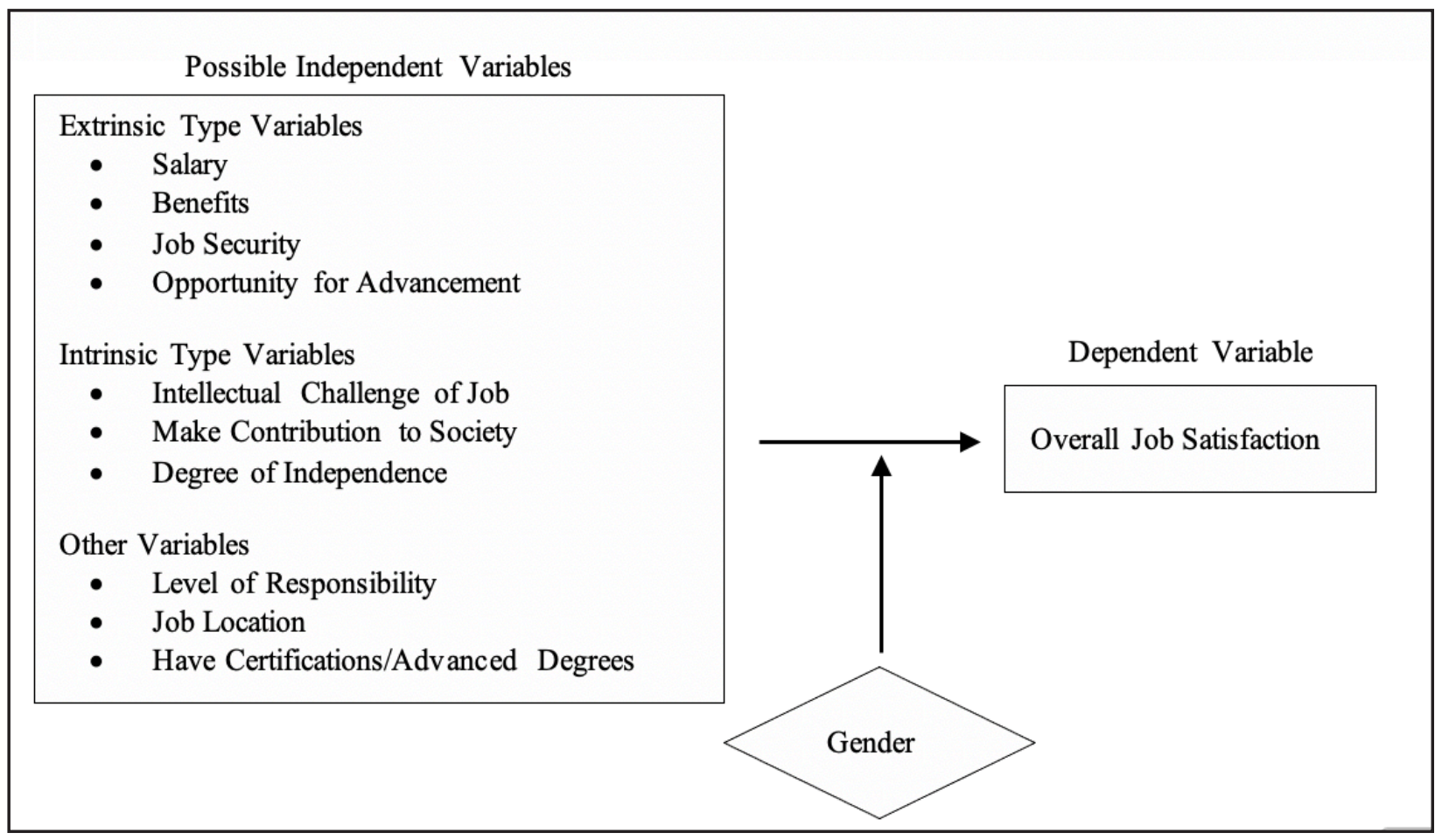

Figure 1: Schematic Diagram of Independent and Dependent Variables 
presents evidence that women are more likely to leave fields that have a predominance of male employees. She also finds that women leave the engineering field at a higher rate than many other fields of employment.

\section{Conceptual Framework}

The conceptual framework (Fig. 1) describes the variables and the process for the variables' possible interrelationship to job satisfaction. The definition of the variables included in addressing the research questions are provided in Table 1.

\section{Findings}

Tables 2 and 3 detail the satisfaction scores for males and females for each of the possible determinants and for the overall satisfaction level. Respondents ranked satisfaction with independence the highest while satisfaction with opportunities for advancement ranked the lowest. Overall job satisfaction scores for males and females did not differ significantly (See Table 4).

Table 1: Variable Definitions

\begin{tabular}{|c|c|c|}
\hline Variable & Conceptual Definition & Operational Definition \\
\hline $\begin{array}{l}\text { Job Relation to Highest } \\
\text { Degree }\end{array}$ & $\begin{array}{l}\text { Self-assessment by respondent as to } \\
\text { whether they are working in their } \\
\text { field of highest degree }\end{array}$ & $\begin{array}{l}3 \text { Point Scale from Closely Re- } \\
\text { lated to Unrelated }\end{array}$ \\
\hline Overall Job Satisfaction & $\begin{array}{l}\text { Assessment of how satisfied respon- } \\
\text { dent was on the date provided in } \\
\text { survey }\end{array}$ & $\begin{array}{l}4 \text { Point Scale from Very Satis- } \\
\text { fied to Very Dissatisfied (col- } \\
\text { lapsed to } 3 \text { levels for ordinal } \\
\text { logistic analysis) }\end{array}$ \\
\hline Salary & $\begin{array}{l}\text { Monetary compensation - Extrinsic } \\
\text { Motivator }\end{array}$ & $\begin{array}{l}4 \text { Point Scale from Very Satis- } \\
\text { fied to Very Dissatisfied }\end{array}$ \\
\hline Job Security & $\begin{array}{l}\text { Low risk of being terminated - Ex- } \\
\text { trinsic Motivator }\end{array}$ & $\begin{array}{l}4 \text { Point Scale from Very Satis- } \\
\text { fied to Very Dissatisfied }\end{array}$ \\
\hline Job Location & $\begin{array}{l}\text { Current location of Current Job - } \\
\text { Classified here as Other Motivator }\end{array}$ & $\begin{array}{l}4 \text { Point Scale from Very Satis- } \\
\text { fied to Very Dissatisfied }\end{array}$ \\
\hline $\begin{array}{l}\text { Opportunity for Advance- } \\
\text { ment }\end{array}$ & $\begin{array}{l}\text { Opportunity for Promotion - Ex- } \\
\text { trinsic Motivator }\end{array}$ & $\begin{array}{l}4 \text { Point Scale from Very Satis- } \\
\text { fied to Very Dissatisfied } \\
\end{array}$ \\
\hline Intellectual Challenge & $\begin{array}{l}\text { Opportunity to think - to have intel- } \\
\text { lectually satisfying work - used here } \\
\text { as a proxy for feelings of competence } \\
\text { - Intrinsic Motivator }\end{array}$ & $\begin{array}{l}4 \text { Point Scale from Very Satis- } \\
\text { fied to Very Dissatisfied }\end{array}$ \\
\hline Level of Responsibility & $\begin{array}{l}\text { Related to being valued - Classified } \\
\text { as Other Motivator }\end{array}$ & $\begin{array}{l}4 \text { Point Scale from Very Satis- } \\
\text { fied to Very Dissatisfied }\end{array}$ \\
\hline Degree of Independence & $\begin{array}{l}\text { The quality or state of being inde- } \\
\text { pendent, free, and self-directing - } \\
\text { Intrinsic Motivator }\end{array}$ & $\begin{array}{l}4 \text { Point Scale from Very Satis- } \\
\text { fied to Very Dissatisfied }\end{array}$ \\
\hline Contribution to Society & $\begin{array}{l}\text { Contributing to society's well-being } \\
\text { - Intrinsic Motivator } \\
\end{array}$ & $\begin{array}{l}4 \text { Point Scale from Very Satis- } \\
\text { fied to Very Dissatisfied }\end{array}$ \\
\hline Financial Certification & $\begin{array}{l}\text { Having a CFP or CFA Certification - } \\
\text { Signal of Competency }\end{array}$ & Binary Yes/No \\
\hline Advanced degree & $\begin{array}{l}\text { Master of Business Administration } \\
\text { Degree or Advanced Degree beyond } \\
\text { the BA/BS Degree - Financial Signal } \\
\text { of Competency }\end{array}$ & Binary Yes/No \\
\hline Gender & Self-Identified Gender & Binary $M / F$ \\
\hline Participation Rate & $\begin{array}{l}\text { Self-Identified - Having financial } \\
\text { management degree and employed } \\
\text { in a field closely related to finance }\end{array}$ & Percentage of total \\
\hline
\end{tabular}


Table 2: Job Satisfaction Ratings for Females in Job Closely or Somewhat Related to Financial Management (4 Point reverse scale with 1 being the highest)

\begin{tabular}{|l|c|c|c|}
\hline \multicolumn{1}{c}{ Variable } & N & Mean & Std. Dev. \\
\hline Job Satisfaction & 170 & 1.723 & 0.745 \\
\hline Salary & 170 & 1.852 & 0.743 \\
\hline Benefits & 170 & 1.805 & 0.830 \\
\hline Security & 170 & 1.752 & 0.805 \\
\hline Location & 170 & 1.582 & 0.789 \\
\hline Opportunities for Advancement & 170 & 2.158 & 0.852 \\
\hline Intellectual Challenge & 170 & 1.817 & 0.847 \\
\hline Level of Responsibility & 170 & 1.711 & 0.733 \\
\hline Degree of Independence & 170 & 1.529 & 0.755 \\
\hline Contribution to Society & 170 & 1.947 & 0.918 \\
\hline
\end{tabular}

Table 5 provides the mean satisfaction scores (M), the correlations, and partial correlations as well as the overall job satisfaction correlations for female financial managers. Among financial manager respondents working in the financial field or closely related to the financial field, we found relatively high to moderately high significant degrees of correlation in the intrinsic motivation areas for females. The correlations for having positions that are intellectually challenging, provide job independence, and job's contribute to society are all .52 or higher, with intellectual challenge having the highest (.68) degree of correlation. An extrinsic motivator, opportunity for advancement, is also a moderately high correlation (.57). Satisfaction with level of responsibility, while not classified here as intrinsic or extrinsic, had the second highest correlation (.64). These levels contrast somewhat with the correlations for males, where the correlations are in the $.46-.51$ range for the more intrinsic motivators (see Table 6). Moreover, the highest correlation among males is opportunity for advancement (.53) closely followed by the need for the job to provide an intellectual challenge (.51). As an added analysis, a comparison of the intrinsic motivator correlations across job functions are found to be more highly correlated with overall job satisfaction in the financial management fields than in the physical sciences, social sciences, or aggregate of all other fields (See Appendix A, Table A1).

\section{Key Findings for Ordinal Logistic Re- gression Analysis}

For total respondents, the likelihood ratio chi-square of 497.8 with a p-value of $<0.0001$ tells us that our model is statistically significant as a whole, as compared to a model with no predictors. The slope esti-

Table 3: Job Satisfaction Ratings for Males in Job Closely or Somewhat Related to Financial Management (4 Point reverse scale with 1 being the highest)

\begin{tabular}{|l|c|c|c|}
\multicolumn{1}{c}{ Variable } & N & Mean & Std Dev \\
\hline Job Satisfaction & 423 & 1.695 & .701 \\
\hline Salary & 423 & 1.829 & .751 \\
\hline Benefits & 423 & 1.783 & .832 \\
\hline Security & 423 & 1.817 & .901 \\
\hline Location & 423 & 1.557 & .791 \\
\hline Opportunities for Advancement & 423 & 2.191 & .922 \\
\hline Intellectual Challenge & 423 & 1.775 & .784 \\
\hline Level of Responsibility & 423 & 1.666 & .699 \\
\hline Degree of Independence & 423 & 1.515 & .708 \\
\hline Contribution to Society & 423 & 1.952 & .833 \\
\hline
\end{tabular}


Table 4: Job Satisfaction Test for Gender Significance

\begin{tabular}{|c|c|c|c|c|c|c|}
\hline \multicolumn{7}{|c|}{ Independent Samples T-Test } \\
\hline & \multirow[b]{2}{*}{$\mathbf{t}$} & \multirow[b]{2}{*}{ df } & \multirow[b]{2}{*}{$\mathbf{p}$} & \multirow[b]{2}{*}{ Cohen's d } & \multicolumn{2}{|c|}{ 95\% CI for Cohen's d } \\
\hline & & & & & Lower & Upper \\
\hline Overall Job Satisfaction & 0.440 & 591 & 0.660 & 0.040 & -0.138 & 0.218 \\
\hline
\end{tabular}

Table 5: Mean Satisfaction scores and Spearmen Correlation Matrix for Females $(n=170)$

\begin{tabular}{lcccccccccc}
\multicolumn{1}{c}{ Variables } & $\mathrm{M}$ & 1 & 2 & 3 & 4 & 5 & 6 & 7 & 8 & 9 \\
1. Overall Job Satisfaction & 1.72 & & & & & & & & & \\
2. Salary & 1.85 & .48 & & & & & & & \\
3. Job Security & 1.75 & .37 & .19 & & & & & & \\
4. Job Location & 1.58 & .38 & .08 & .44 & & & & & \\
5. Opportunities for Ad- & 2.15 & .57 & .40 & .33 & .32 & & & & \\
vancement & & & & & & & & \\
6. Intellectual Challenge & 1.82 & .68 & .41 & .24 & .30 & .63 & & & \\
7. Level of Responsibility & 1.71 & .64 & .44 & .20 & .25 & .56 & .74 & & \\
8. Degree of Independence & 1.52 & .52 & .34 & .27 & .27 & .36 & .48 & .54 & & \\
9. Contribution to Society & 1.94 & .58 & .30 & .27 & .24 & .41 & .56 & .60 & .26 & \\
10. Benefits & 1.80 & .34 & .49 & .44 & .18 & .43 & .39 & .34 & .24 & .28 \\
\hline
\end{tabular}

Note. All correlations significant at the .01 level with the following exceptions: $2 \& 4$, not significant. 4\&10, significant at .05 level.

mates and significance levels are provided in Table 7 for the driving factors.

Based on the estimates from the logistic regression procedure, we conclude that seven significant factors drive the overall job satisfaction among financial managers: salary, job's intellectual challenge, job's degree of independence, job security, job's contribution to society, opportunity for advancement, and job lo- cation. Several factors (benefit, having advanced degrees or financial certifications) are not deemed to be significant determinants; therefore, I excluded them from the final analysis. We include the gender dummy in the final model to show that when controlling for the other variables gender did not play a significant role in determining overall job satisfaction. I later develop a separate female model to investigate

Table 6: Mean Satisfaction scores and Spearmen Correlation Matrix for Males $(n=423)$

\begin{tabular}{lcccccccccc}
\multicolumn{1}{c}{ Variables } & $\mathrm{M}$ & 1 & 2 & 3 & 4 & 5 & 6 & 7 & 8 & 9 \\
\hline 1. Overall Job Satisfaction & 1.69 & & & & & & & & & \\
2. Salary & 1.83 & .46 & & & & & & & \\
3. Job Security & 1.82 & .49 & .26 & & & & & & & \\
4. Job Location & 1.56 & .36 & .20 & .26 & & & & & \\
5. Opportunities for Advancement & 2.19 & .53 & .26 & .46 & .29 & & & & & \\
6. Intellectual Challenge & 1.77 & .51 & .31 & .26 & .25 & .55 & & & \\
7. Level of Responsibility & 1.67 & .48 & .24 & .31 & .26 & .53 & .68 & & & \\
8. Degree of Independence & 1.51 & .46 & .19 & .39 & .27 & .38 & .42 & .51 & & \\
9. Contribution to Society & 1.95 & .50 & .26 & .32 & .26 & .35 & .44 & .39 & .36 & \\
10. Benefits & 1.78 & .31 & .42 & .38 & .24 & .22 & .14 & .11 & .12 & .22 \\
\hline
\end{tabular}

Note. All correlations significant at least the .01 level with the following exceptions: $7 \& 10$, significant at .05 level. 
Table 7: Model 1 - Ordinal Logistic Regression - Determinants of Job Satisfaction Among All Respondents Degreed in Finance - In a Closely/Somewhat Related Profession (N= 593)

\begin{tabular}{|l|c|c|c|}
\multicolumn{1}{|c}{ Parameter } & Estimate & Standard & Prror \\
\hline Intercept 3 & -13.7974 & 0.8442 & $<.0001$ \\
\hline Intercept 2 & -8.8432 & 0.6054 & $<.0001$ \\
\hline Salary & 1.1201 & 0.1538 & $<.0001$ \\
\hline Job Security & 0.7265 & 0.1347 & $<.0001$ \\
\hline Location & 0.4527 & 0.1351 & 0.0008 \\
\hline $\begin{array}{l}\text { Opportunity for Advance- } \\
\text { ment }\end{array}$ & 0.5661 & 0.1490 & 0.0001 \\
\hline Intellectual Challenge & 0.9177 & 0.1686 & $<.0001$ \\
\hline Degree of Independence & 0.8143 & 0.1633 & $<.0001$ \\
\hline Contribution to Society & 0.7238 & 0.1399 & $<.0001$ \\
\hline Gender & 0.1201 & 0.2264 & 0.5956 \\
\hline
\end{tabular}

Note: Standard interpretation of an ordered logit coefficients is that for a one unit increase in the predictor, the dependent variable level is expected to change by its respective regression coefficient in the ordered logit scale while the other variables in the model are held constant.

the primary determinants of satisfaction among that segment.

Based on the model coefficients, for a one unit increase in salary satisfaction (i.e., going from 1 to 2 ), we expect a 1.12 increase in the log odds of being in a higher level of satisfaction, given that all the other variables in the model are held constant. For a one unit increase in the job being an intellectual challenge, we expect a .92 increase in the log odds of being in a higher level of job satisfaction, given that all the other variables in the model are held constant. Likewise, we find the degree of independence the job accords is also important and has the third highest coefficient (.81).

Examining the odds ratio estimates for the total respondent model (Table 8), we conclude that for a one unit increase in salary (i.e., going from 1 to 2 ), the odds of high level of satisfaction versus the combined middle and low categories are 3.07 greater, given that all the other variables in the model are held constant. Likewise, the odds of the combined middle and high categories versus low is 3.07 times greater, given that all the other variables in the model are held constant. For a one unit increase in the job providing an intellectual challenge, the odds of a high level of job satisfaction versus the combined middle and low job satisfaction categories are 2.50 greater, assuming all other variables in the model are constant. For the total respondent sample, the largest odds ratios are for the variables, salary, job's intellectual challenge, salary, and the jobs level of independence afforded. The percent concordant for a model only considering significant factors and gender is $91.4 \%$
Addressing female financial managers separately, the final model yields a likelihood ratio chi-square of 158.4 with a p-value of 0.0001 . The slope estimates and significance levels are provided in Table 9 for the driving factors among female financial managers.

Using an ordered logistic regression procedure, we conclude that five significant factors drive the overall job satisfaction among female financial managers: job's intellectual challenge, job's degree of independence, salary, job security, and job's contribution to society. Four factors (job location, job's opportunity for advancement, job's level of responsibility, and benefits) are not deemed to be significant determinants, so we exclude them from the final analysis. We also fail to find significance for the variables relating to having advanced degrees or financial certifications (See Table 9 for details).

Examining the odds ratio estimates for the female model (Table 10), we conclude that for a one unit increase in salary (i.e., going from 1 to 2), the odds of high level of satisfaction versus the combined middle and low categories are 2.49 greater, given that all the other variables in the model are held constant. Likewise, the odds of the combined middle and high categories versus low is 2.49 times greater, given that all the other variables in the model are held constant. For a one unit increase in the job providing an intellectual challenge, the odds of a high level of job satisfaction versus the combined middle and low job satisfaction categories are 6.41 greater, assuming all other variables in the model are constant. For females, the largest odds ratios are for the variables job's intellectual challenge, level of independence, and salary. The female final model includes two variables 
Table 8: Odds Ratio Estimates - Total Respondents Job Satisfaction Factors ( $\mathrm{N}=593)$

\begin{tabular}{|l|c|c|c|}
\hline \multicolumn{1}{c}{ Effect } & Point Estimate & \multicolumn{2}{c|}{$\begin{array}{c}\text { 95\% Wald Confidence } \\
\text { Limits }\end{array}$} \\
\hline Salary & 3.065 & 2.268 & 4.144 \\
\hline Job Security & 2.068 & 1.588 & 2.693 \\
\hline Location & 1.573 & 1.207 & 2.049 \\
\hline $\begin{array}{l}\text { Opportunity for Advance- } \\
\text { ment }\end{array}$ & 1.761 & 1.315 & 2.359 \\
\hline Intellectual Challenge & 2.504 & 1.799 & 3.484 \\
\hline Degree of Independence & 2.258 & 1.639 & 3.109 \\
\hline Contribution to Society & 2.062 & 1.568 & 2.713 \\
\hline Gender & 1.128 & 0.724 & 1.757 \\
\hline
\end{tabular}

(salary and job security) that are considered extrinsic motivators and three (job's intellectual challenge, job's level of independence, and job's contribution to society) that may be considered intrinsic motivators. Developing a model for male financial managers and comparing that model to the female model reveals that two additional variables are significant among males: opportunity for advancement and job location; both were deemed significant in the overall model
(Model 1). Table 11 summarizes the comparison of the female and male models via their respective odds ratio estimates. The models share five similar drivers and neither model includes having advanced degrees or certifications as determinants of job satisfaction.

Among females, the percent concordant for a model only considering significant factors is $90.9 \%$. Similarly, the concordance percentage for the male model is $91.3 \%$.

Table 9: Ordinal Logistic Regression results relating Job Satisfaction Factors to Overall Job Satisfaction Among Female Respondents Degreed in Finance - In a Closely/Somewhat Related Profession $(\mathrm{N}=170)$

\begin{tabular}{|l|c|c|c|}
\multicolumn{1}{c}{ Variable } & Estimate & \multicolumn{1}{c}{ SE } & Pr $>$ ChiSq \\
\hline Intercept 3 & -12.44 & 1.4 & $<.0001$ \\
\hline Intercept 2 & -8.06 & 1.0 & $<.0001$ \\
\hline Salary & .91 & .31 & .003 \\
\hline Job Security & .70 & .25 & .007 \\
\hline Intellectual Challenge & 1.86 & .33 & $<.0001$ \\
\hline Degree of Independence & .96 & .32 & .002 \\
\hline Contribution to Society & .61 & .25 & .01 \\
\hline
\end{tabular}

Note: Proportional odds assumption satisfied, Global Null Hypothesis rejected at $<.0001$ level. $\mathrm{N}=170$

Table 10: Odds Ratio Estimates - Female Job Satisfaction Factors $(\mathrm{N}=170)$

\begin{tabular}{|l|c|c|c|}
\multicolumn{2}{c}{ Variable } & Point Estimate & \multicolumn{2}{c|}{ 95\% Wald Confidence Limits } \\
\hline Salary & 2.49 & 1.37 & 4.54 \\
\hline Job Security & 2.02 & 1.22 & 3.36 \\
\hline Intellectual Challenge & 6.41 & 3.31 & 12.42 \\
\hline Degree of Independence & 2.61 & 1.41 & 4.87 \\
\hline Contribution to Society & 1.85 & 1.12 & 3.04 \\
\hline
\end{tabular}


Table 11: Odds Ratio Comparisons Job Satisfaction Factors - Female (N=170) vs. Male $(\mathrm{N}=423)$

\begin{tabular}{|l|c|c|}
\hline \multicolumn{1}{|c|}{ Variable } & 2.49 & 3.11 \\
\hline Salary & 2.02 & 2.27 \\
\hline Job Security & 6.41 & 2.05 \\
\hline Intellectual Challenge & 2.61 & 2.14 \\
\hline Degree of Independence & 1.85 & 2.13 \\
\hline Contribution to Society & NS & 1.59 \\
\hline Location & NS & 1.80 \\
\hline $\begin{array}{l}\text { Opportunity for Advance- } \\
\text { ment }\end{array}$ & & Point Estimate \\
\hline
\end{tabular}

Note: $\mathrm{NS}=$ Not a significant factor. $\mathrm{n}=170$ for females and $\mathrm{n}=593$ for males

\section{Discussion}

My primary objective was to delineate the drivers of job satisfaction among male and female financial degreed respondents working in financial management or a related position. Factors associated with overall job satisfaction tend to have higher correlations with intrinsic type motivators as opposed to the extrinsic motivators (although opportunity for advancement was a relatively high correlate). Despite an anticipated difference between genders, the result of the highest correlate for males is the job's opportunity for advancement was surprising. The finding worthy of further exploration was that correlations tend to be higher among females in the financial sector for factors deemed intrinsic motivators.

The finding that there was no difference in overall job satisfaction between female and male financial managers is consistent with Vansteenkiste et al. (2007), but at odds with the studies by Bender et al. (2005), Sousa-Poza and Sousa-Poza (2000), and Sloane and Williams (2000).

The results from the multiple ordinal logistic regression analyses somewhat mirror those from the correlation analyses. However, the extrinsic reward variable salary yielded the highest point estimate coefficient. This result was driven by the male segment of the sample. The next two highest coefficients, intellectual challenge and independence, are considered more intrinsic motivators. Similar results regarding the intrinsic type motivators were found by Gillet et al. (2013). The results regarding the extrinsic motivators salary and job security on job satisfaction are consistent with Cho and Perry (2012), Kuvaas (2006), Linz and Semykina (2012), and O'Driscoll and Randall (1999). Contrarily, Terera and Ngirande (2014) conclude that rewards correlated positively with job retention but not with work satisfaction.

Among female financial managers and controlling for the other factors, we found the variable job's intellectual challenge (a possible proxy for the construct, competence) as the most significant determinant of higher overall job satisfaction. This result is important as many women may not be fully engaged in the field because they are not in jobs providing this challenge. They may be pushed to less challenging jobs that are only somewhat related to finance. We also conclude that the level of job independence is the next highest driver of satisfaction. These variables are followed in importance by two extrinsic variables: salary and job security. The variable level of responsibility had a high correlation with job satisfaction for females and a moderate correlation for males, but this factor was not statistically significant in the regression analysis once the other variables were controlled. Lastly, the variable contribution to society, a variable that can also be viewed as intrinsic, was also deemed significant.

Therefore, the first hypothesis (H1) is confirmed. The intrinsic motivation factor intellectual challenge will be associated positively with overall job satisfaction among male and female financial managers employed in financial management.

Likewise, the second hypothesis (H2) is confirmed. The intrinsic motivation factor degree of independence is associated positively with overall job satisfaction among male and female financial managers employed in financial management.

The third hypothesis (H3) stated that the determinants of job satisfaction level would be the same for males and females. Here, we find correlates among females differ in magnitude from their male counterparts. However, our gender dummy variable in Model 1 was not a significant predictor of job satisfaction. Overall, we found minor differences in the drivers of female satisfaction factors versus the male satisfaction drivers. Males and females share the aforementioned five variables as determinants. The male model included one additional extrinsic motivator, job's opportunity for advancement, and another variable, job location. We reject the second hypothesis and conclude that male and female financial managers have differing drivers of job satisfaction. 
I am surprised by the negative results (in both models) of the variables involving more advanced education. I believed that having a financial certification or advanced degree would serve as another proxy for competence and influence the overall job satisfaction of the managers. I intend to test this aspect among financial advisors in the next study.

\section{Limitations and Future Research}

The research is subject to several limitations. Due to the database question/answer limitations, we are unable to completely incorporate a comprehensive list of intrinsic and extrinsic motivators that may serve to drive female financial managers' work satisfaction. That is, the factors that contribute to autonomy, relatedness, and competence are not addressed in the government's educational database to the extent we would prefer and to the extent the topic demands. This limitation also prohibits us from aggregating the intrinsic and extrinsic motivators as factors and conducting the appropriate EFA and Cronbach's alpha analyses. The areas for future research are apparent and important if we are to create the interventions necessary in the financial management field that can create more positive female retention

rates. Those areas are:

1. Refine the analysis to the financial services sector since the women retention issue has been reported to be quite pronounced among female financial planners.

2. Develop the independent variables and the advancement of knowledge in this field by utilizing the full Motivation at Work Scales (Gagné et al. 2015) to help explain the female exodus from financial services. We will ascertain the association between SDT related variables and outcome variables, such as job satisfaction, affective work commitment and turnover intention in the financial services domain.

3. Utilize more complex forms of extrinsic motivators (such as integrated motivation) that were not available from the present survey data. These forms can be addressed in a custom survey to the financial planner population.

4. Consider the use of a structural equations model approach.

We also consider the development of a separate study that will be longitudinal in nature. This study would help determine whether the current female job participation rate among those educated in finance has been increasing or remaining stagnant over the recent past. The government dataset we use in this study is expected to apply to this future study.

\section{Conclusions}

When considering the possible drivers of job satisfaction among female financial managers in a job closely or somewhat related to their degree, we find relatively high correlations with intrinsic type motivators (e.g., need for independence, the need to be intellectually challenged, and the need for contributing to society), as opposed to more reward-oriented motivators, such as benefits, salary, and job security. Likewise, when conducting an ordinal logistic regression analysis, we find the intrinsic motivator (being intellectually challenged) as the most significant determinant of job satisfaction among females. The models of job satisfaction for males and females separately share five variables, three of which can be considered intrinsic type motivators. The regression model for male financial managers includes two additional factors, which help to explain the levels of overall job satisfaction.

This study advances knowledge through the development of factors that drive job satisfaction among financial management professionals. It also serves to illustrate the role SDT might play in determining the factors driving overall work satisfaction in the financial management sector. Research has shown that elements of SDT apply to driving job retention and well-being in other professional fields. Therefore, I take a step in addressing a gap in the literature through application of those elements of SDT that were available to the public in the U.S. database that was utilized in this study.

The implications for practice are related to the methods by which financial managers are managed and the types of incentives utilized to foster success for the firm. Without the proper incentives and management techniques being applied in the financial sectors, large sums of monies dedicated to attracting females (for instance) to financial positions may be misapplied. Major financial firms have stated publicly their interest in promoting females to their organizations; however, despite these goals, females leave the sector at disproportionately higher rates. It may be that the job satisfaction programs offered in the financial services sector are not consistent with female retention objective. Our ultimate goal is to create an intervention in the job sector that will lead to improvements in the retention rate of financially trained female executives. This research is the first step of three that we have planned to that end. 


\section{References}

Baard, P. P., Deci, E. L., \& Ryan, R. M. (2004). Intrinsic need satisfaction: A motivational basis of performance and weil-being in two work settings 1. Journal of Applied Social Psychology, 34(10), 2045-2068.

Bender, K. A., Donohue, S. M., \& Heywood, J. S. (2005). Job satisfaction and gender segregation. Oxford Economic Papers, 57(3), 479-496. https:// doi.org/10.1093/oep/gpi015

CFP Board. (2019). Retrieved from https://www.cfp. net/knowledge/reports-and-statistics/professional-demographics

Chandler, C. (2016). The best schools for financial planning. Investopedia. https://www.investopedia.com/articles/financial-advisors/012215/ best-schools-financial-planning.asp

Cho, Y. J., \& Perry, J. L. (2012). Intrinsic motivation and employee attitudes: Role of managerial trustworthiness, goal directedness, and extrinsic reward expectancy. Review of Public Personnel Administration, 32(4), 382-406. https://doi. org/10.1177/0734371X11421495

Deci, E. L., Ryan, R. M., Gagne, M., Leone, D. R., Usunov, J., \& Kornazheva, B. P. (2001). Need satisfaction, motivation, and well-being in the work organizations of a former eastern bloc country: A cross-cultural study of self-determination. Personality \& Social Psychology Bulletin (8). https:// doi.org/10.1177/0146167201278002

Gagné, M., \& Deci, E. (2005). Self-Determination Theory and work motivation. Journal of Organizational Behavior, 26(4), 331-362. https://doi. org/10.1002/job.322

Gagné, M., Forest, J., Vansteenkiste, M., Crevier-Braud, L., Van den Broeck, A., Aspeli, A. K., \& Güntert, S. T. (2015). The multidimensional work motivation scale: Validation evidence in seven languages and nine countries. European Journal of Work and Organizational Psychology, 24(2), 178-196. https://doi.org/10.1080/135943 2X.2013.877892

Gillet, N., Gagne, M., Sauvagere, S., \& Fouquereau, E. (2013). The role of supervisor autonomy support, organizational support, and autonomous and controlled motivation in predicting employees' satisfaction and turnover intentions. European Journal of Work and Organizational Psychology, 22(4), 450-460. https://doi.org/10.1080/13594 $32 \mathrm{X} .2012 .665228$

Güntert, S. T. (2015). The impact of work design, autonomy support, and strategy on employee outcomes: A differentiated perspective on self-determination at work. Motivation and Emotion, 39(1),
74-87. https://doi.org/10.1007/s11031-014-94127

Herzberg, F., Mausner, B., \& Snyderman, B. (1959). The motivation to work (2nd ed.). Oxford, England: John Wiley \& Sons.

Hunt, J. (2016). Why do women leave science and engineering? ILR Review, 69(1), 199-226. https:// doi.org/10.1177/0019793915594597

Kuvaas, B. (2006). Work performance, affective commitment, and work motivation: The roles of pay administration and pay level. Journal of Organizational Behavior: The International Journal of Industrial, Occupational and Organizational Psychology and Behavior, 27(3), 365-385. https://doi. org/10.1002/job.377

Lambert, E., \& Hogan, N. (2009). The importance of job satisfaction and organizational commitment in shaping turnover intent: A test of a causal model. Criminal Justice Review, 34(1), 96-118. https:// doi.org/10.1177/0734016808324230

Linz, S. J., \& Semykina, A. (2012). What makes workers happy? Anticipated rewards and job satisfaction. Industrial Relations: A Journal of Economy and Society, 51(4), 811-844. https://doi. org/10.1111/j.1468-232X.2012.00702.x

Mattia, M., (2020). Embargoed Dissertation. Work Motivation in Wealth Management. The Role of Self Determination Theory. The University of South Florida.

Mercer Study. (2016). When women thrive. gender diversity is an imperative for the financial services industry. Mercer.

Meyer, J. P., Allen, N. J., \& Smith, C. A. (1993). Commitment to organizations and occupations: Extension and test of a three-component conceptualization. Journal of Applied Psychology, 78(4), 538. https://doi.org/10.1037/0021-9010.78.4.538

Meyer, J. P., \& Gagne, M. (2008). Employee engagement from a Self-Determination Theory perspective. Industrial and Organizational Psychology, 1(1), 60-62. https://doi.org/10.1111/ j.1754-9434.2007.00010.x

Neck, C. (2015). Disappearing women: Why do women leave senior roles in finance? Further evidence. Australian Journal of Management, 40(3), 511. https://doi.org/10.1177/0312896215578015

O’Driscoll, M. P., \& Randall, D. M. (1999). Perceived organizational support, satisfaction with rewards, and employee job involvement and organizational commitment. Applied Psychology, 48(2), 197209. https://doi.org/10.1111/j.1464-0597.1999. tb00058.x

Pepe, M. (2010). The impact of extrinsic motivational dissatisfiers on employee level of job satisfaction 
and commitment resulting in the intent to turnover. Journal of Business \& Economics Research, 8(9). https://doi.org/10.19030/jber.v8i9.762

Ryan, R. M., \& Deci, E. L. (2000). Self-Determination Theory and the facilitation of intrinsic motivation, social development, and well-being. American Psychologist, 55(1), 68. https://doi. org/10.1037/0003-066X.55.1.68

Sloane, P. J., \& Williams, H. (2000). Job satisfaction, comparison earnings, and gender. Labour, 14(3), 473-502. https://doi.org/10.1111/14679914.00142

Sousa-Poza, A., \& Sousa-Poza, A. A. (2000). Taking another look at the gender/job-satisfaction paradox. Kyklos, 53(2), 135-152. https://doi. org/10.1111/1467-6435.00114

Stefko, R., Bacik, R., Fedorko, R., Gavurova, B., Horvath, J., \& Propper, M. (2017). Gender differences in the case of work satisfaction and motivation. Polish Journal of Management Studies, 16. https:// doi.org/10.17512/pjms.2017.16.1.18

Terera, S. R., \& Ngirande, H. (2014). The impact of rewards on job satisfaction and employee retention. Mediterranean Journal of Social Sciences, 5(1), 481. https://doi.org/10.5901/mjss.2014. v5n $1 \mathrm{p} 481$

Thompson, C. A., \& Prottas, D. J. (2006). Relationships among organizational family support, job autonomy, perceived control, and employee well-being. Journal of Occupational Health Psy- chology, 11(1), 100. https://doi.org/10.1037/10768998.10.4.100

Van den Broeck, A., Ferris, D. L., Chang, C. H., \& Rosen, C. C. (2016). A review of Self-Determination Theory's basic psychological needs at work. Journal of Management, 42(5), 1195-1229. https://doi. org/10.1177/0149206316632058

Vansteenkiste, M., Neyrinck, B., Niemiec, C. P., Soenens, B., De Witte, H., \& Van den Broeck, A. (2007). On the relations among work value orientations, psychological need satisfaction and job outcomes: A Self-Determination Theory approach. Journal of Occupational and Organizational Psychology, 80(2), 251-277. https://doi. org/10.1348/096317906X111024

Williams, L. J., \& Hazer, J. T. (1986). Antecedents and consequences of satisfaction and commitment in turnover models: A reanalysis using latent variable structural equation methods. Journal of Applied Psychology, 71(2), 219. https://doi. org/10.1037/0021-9010.71.2.219

\section{Review}

This article was accepted under the constructive peer review option. For futher details, see the descriptions at:

http://mumabusinessreview.org/peer-review-options/

\section{Author}

\begin{tabular}{|l|l|}
\hline & $\begin{array}{l}\text { Mark Mattia is a Mathematics Instructor at the Pine View School for the Gifted } \\
\text { in Sarasota Florida where he primarily teaches Statistics. Prior to this position he } \\
\text { was CMO at a major science museum and spent nearly nineteen years at Mars } \\
\text { Inc. finishing his career there as a VP Marketing. He holds a DBA degree from } \\
\text { the Muma College of Business, University of South Florida, an MS in Mathemat- } \\
\text { ics from the New Jersey Institute of Technology, and a BA degree in Mathematics } \\
\text { from the University of Colorado. He currently resides in Sarasota Florida with his } \\
\text { wife Dr. Laura Mattia and his two daughters. }\end{array}$ \\
\hline
\end{tabular}




\section{Appendix A}

Table A1: Correlations of key Job Satisfaction factors with Overall Job Satisfaction for Females in Jobs Closely or Somewhat Related to the Specific Field Indicated (4 Point reverse scale with 1 being the highest)

\begin{tabular}{|l|c|c|c|}
\hline \multicolumn{1}{|c}{ Variable } & Finance & Social Sciences & Physical Sciences \\
\hline Salary & .48 & .46 & .51 \\
\hline Job Security & .37 & .37 & .36 \\
\hline Job Location & .38 & .28 & .35 \\
\hline Opportunity for Advancement & .57 & .52 & .54 \\
\hline Intellectual Challenge & .68 & .54 & .52 \\
\hline Level of Responsibility & .64 & .53 & .49 \\
\hline Degree of Independence & .52 & .45 & .47 \\
\hline Contribution to Society & .58 & .39 & .42 \\
\hline Benefits & .34 & .26 & .42 \\
\hline
\end{tabular}

